The authors reported no conflicts of interest.

The Journal policy requires editors and reviewers to disclose conflicts of interest and to decline handling or reviewing manuscripts for which they may have a conflict of interest. The editors and reviewers of this article have no conflicts of interest.

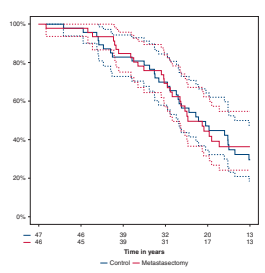

\section{TUMOR BIOLOGY IS A MAJOR DETERMINANT OF SURVIVAL AFTER PULMONARY}

\section{METASTASECTOMY FOR COLORECTAL CANCER \\ To the Editor:}

Corsini and colleagues add further evidence that survival with metastatic diseases is dominated by cancer biology. The large difference in survival after pulmonary metastasectomy with right-sided versus left-sided colorectal cancer (CRC) (hazard ratio [HR], 0.31; $P=.036)$ adds new knowledge about what determines survival with pulmonary metastases. ${ }^{1}$ The prognostic factors-number of metastases, interval since primary resection, previous liver involvement, mediastinal nodes, carcinoembryonic antigen-are all well known. They contribute to selection of patients for metastasectomy. Based on this new evidence, the side of the primary CRC should be added as a prognostic indicator for pulmonary metastasectomy "especially if the patients are borderline surgical candidates or inclined to avoid surgical management."

This effect is larger than the likely effect of pulmonary metastasectomy itself. The randomized controlled trial (RCT) Pulmonary Metastasectomy in Colorectal Cancer (PulMiCC) to which the authors refer has shown that any difference attributable to surgery cannot be as great as is widely believed. ${ }^{2}$ PulMiCC included minimization, which is more practical than stratification in surgical trials, where inherent difficulties in recruitment result in fewer participants. Remote randomization included TNM stage

\footnotetext{
The Editor welcomes submissions for possible publication in the Letters to the Editor section that consist of commentary on an article published in the Journal or other relevant issues. Authors should: • Include no more than 500 words of text, three authors, and five references. $\bullet$ Type with double-spacing. • See http://jtcs.ctsnetjournals.org/ misc/ifora.shtml for detailed submission instructions. • Submit the letter electronically via jtcvs.editorialmanager.com. Letters commenting on an article published in the JTCVS will be considered if they are received within 6 weeks of the time the article was published. Authors of the article being commented on will be given an opportunity of offer a timely response ( 2 weeks) to the letter. Authors of letters will be notified that the letter has been received. Unpublished letters cannot be returned.
}

in addition to the factors mentioned, which provided excellent balance for known confounders. At the time, laterality of the primary was not known to us as a confounder, but with an effect of this magnitude it is good sense to include it in balancing the arms in study NCT03599752.

The PulMiCC challenges the consensus belief that without metastasectomy, 5-year survival would be zero. ${ }^{2}$ For controls, the median survival was 3.8 years, compared with 3.5 years after metastasectomy, but 93 patients was insufficient to show noninferiority-which was the basis of the power calculation-of management without metastasectomy (HR, 0.93; 95\% confidence interval [CI], 0.56-1.56). Nevertheless, pooled with the CLOCC trial, which included nonintervention for CRC metastases, control survival was 30\% (95\% CI, 21\%-40\%), with ample power to refute the zero survival assumption or any estimate approaching it. ${ }^{4}$

Corsini and colleagues refer to the design of NCT03599752, which results in all patients undergoing lung metastasectomy. In some patients, metastasectomy is deferred until after chemotherapy, so this is really a trial of sequencing. It will not add to knowledge about the effect of metastasectomy itself. If metastasectomy were a new drug, it would not be allowed into practice on existing evidence. Whether or not patients are "inclined to avoid surgical management," they are entitled to more realistic evidence-based estimates of the effect size of benefit from metastasectomy than has hitherto been the case. ${ }^{5}$

\author{
Norman R. Williams, $P h D^{a}$ \\ Fergus Macbeth, $D M^{b}$ \\ Tom Treasure, $M D^{c}$ \\ ${ }^{a}$ Surgical and Interventional Trials Unit \\ ${ }^{c}$ Clinical Operational Research Unit \\ University College London \\ London, United Kingdom \\ ${ }^{b}$ Centre for Trials Research \\ Cardiff University \\ Cardiff, United Kingdom
}

\title{
References
}

1. Corsini EM, Mitchell KG, Correa A, Morris VK, Antonoff MB, MD Anderson Pulmonary Metastasectomy Working Group. Effect of primary colorectal cancer tumor location on survival after pulmonary metastasectomy. J Thorac Cardiovasc Surg. 2021;162:296-305.

2. Milosevic M, Edwards J, Tsang D, Dunning J, Shackcloth M, Batchelor T, et al Pulmonary metastasectomy in colorectal cancer: updated analysis of 93 randomized patients - control survival is much better than previously assumed. Colorectal Dis. 2020;22:1314-24.

3. Ruers T, van Coevorden F, Punt CJ, Pierie JE, Borel-Rinkes I, Ledermann JA, et al. Local treatment of unresectable colorectal liver metastases: results of a randomized phase ii trial. J Natl Cancer Inst. 2017;109:djx015.

4. Baum M, Fallowfield L, Farewell V, Macbeth F, Treasure T. NICE guidelines: management of colorectal cancer metastases. Br J Surg. 2020;107:e357. 